\title{
SOBRE CONFLITOS AMBIENTAIS E EDUCAÇÃO AMBIENTAL
}

\author{
Marco Antonio Sampaio Malagodi ${ }^{1}$
}

Resumo: O presente artigo apresenta e discute algumas possibilidades de abordagem dos conflitos ambientais a partir de uma educação ambiental crítica, contextualizando as trajetórias e escolhas políticas e metodológicas que favorecem alguma convergência entre os campos de pesquisa e ação. Para tanto, considero os conflitos ambientais como conflitos sociais, apresento três diferentes visões sobre os conflitos e elejo uma delas como a mais próxima da vertente da educação ambiental crítica, provocando uma reflexão sobre democracia e política, diferenciando as noções de pluralidade social e desigualdade social. Com base nesses pressupostos, destaco uma das possibilidades de conceituação dos conflitos ambientais. $\mathrm{Na}$ última parte, levanto algumas questões metodológicas para maior coerência na aproximação desses campos e aponto alguns eixos para o debate, sugerindo também materiais e outras fontes de informação para aprofundamento.

Palavras-chave: Conflitos ambientais. Educação ambiental crítica. Justiça ambiental.

\section{ON ENVIRONMENTAL CONFLICTS AND ENVIRONMENTAL EDUCATION}

\begin{abstract}
This paper presents some approaches to environmental conflicts based on critical environmental education, contextualizing political and methodological trajectories and choices that contribute to bringing together the fields of research and action. In order to do so, we define environmental conflicts as social conflicts, presenting three different perspectives about the conflicts and choosing one of them as the nearest branch to critical environmental education, which leads to a reflection on the ideas of democracy and politics, highlighting the differences between the notions of social diversity and social inequality. Under these assumptions, we point out one of the possibilities to conceptualize environmental conflicts. Finally, we raise some methodological questions to approach these fields with more coherence, and propose some axes to the debate, also suggesting materials and other sources of information for further studies.
\end{abstract}

Keywords: Critical environmental education. Environmental conflicts. Environmental justice.

\section{SOBRE CONFLICTOS AMBIENTALES Y EDUCACIÓN AMBIENTAL}

Resumen: Este artículo presenta y discute algunas posibilidades de abordaje de los conflictos ambientales a partir de una educación ambiental crítica, contextualizando las trayectorias y elecciones políticas y metodológicas que favorecen alguna convergencia entre los campos de investigación y acción. Para esto, considero los conflictos ambientales como conflictos sociales, presento tres diferentes visiones sobre los conflictos y elijo una de ellas como la más próxima de la vertiente de la educación ambiental crítica, provocando

\footnotetext{
${ }^{1}$ Engenheiro agrônomo, mestre em Ciências Florestais, doutor em Psicologia,Professor Adjunto no Curso de Geografia da Universidade Federal Fluminense(UFF),pesquisador do Núcleo de Estudos Socioambientail , Campos dos Goytacazes, Rio de Janeiro, Brasil, marcomalagodi@,uol.com.br
} 
una reflexión sobre democracia y política, diferenciando las nociones de pluralidad social y desigualdad social. Con base en estos presupuestos, destaco una de las posibilidades de conceptuación de los conflictos ambientales. En la última parte, levanto algunas cuestiones metodológicas para mayor coherencia en la aproximación de estos campos y apunto algunos ejes para el debate, sugiriendo también materiales y otras fuentes de información para el perfeccionamiento.

Palabras clave: Conflictos ambientales. Educación ambiental crítica. Justicia ambiental.

\section{Proximidades e distâncias entre os conflitos ambientais e a educação ambiental}

Embora seja relativamente recente, a consolidação do tema dos conflitos ambientais como objeto de estudo das ciências sociais, o fenômeno ao qual esse termo faz referência pode ser reconhecido hoje como um fato antigo na história da humanidade (ALIER, 2007). A proximidade da educação ambiental (EA) brasileira com esse tema não é algo tão novo, se considerarmos que ela tem raízes nos movimentos ecológicos e de contracultura que emergiram no âmbito internacional (desde os anos 1960) e nacional (décadas de 1970 e 1980), quando ganhou destaque a denúncia dos riscos e impactos ambientais do modo de vida das sociedades industriais modernas (CARVALHO, 2008). Em suas ações, os movimentos ecológicos já buscavam "chamar a atenção para a finitude e a má distribuição no acesso aos recursos naturais e envolver os cidadãos em ações sociais ambientalmente apropriadas" (CARVALHO, 2008, p. 52); porém, muitas das lutas populares e movimentos sociais no Brasil ainda não consideravam os típicos problemas urbanos e sociais que enfrentavam como problemas ambientais (LIMA, 2011). Nessa época, no Brasil, o contexto político autoritário, a grande influência de ideias desenvolvimentistas entre as elites dirigentes, a consideração da temática ambiental como algo supérfluo e a predominância de uma visão de natureza apenas "natural" (desumanizada) dificultavam ainda mais a articulação das agendas ambiental e social entre os diferentes movimentos de luta (LIMA, 2011).

Foi apenas no período da redemocratização brasileira, em meados dos anos 1980, que começaram a se formar alianças significativas entre entidades ambientalistas e movimentos sociais no Brasil (LIMA, 2011), na mesma época em que a educação popular pôde perceber a importância de sua participação no enfrentamento da questão ambiental (LAYRARGUES, 2000). Estava se estruturando o socioambientalismo brasileiro, e desse diálogo nasceu nos anos 1990 uma grande articulação que desembocou na criação do Fórum de ONGs e Movimentos Sociais, que viria a organizar o movimento preparatório para os debates do Fórum Global, evento paralelo e crítico à Conferência da ONU sobre Desenvolvimento e Meio Ambiente, a Rio-92 (SCOTTO; CARVALHO; GUIMARÃES, 2007). Entre os muitos documentos que tal fórum produziu está o Tratado de Educação Ambiental para Sociedades Sustentáveis e Responsabilidade Global, o marco político para o projeto pedagógico da EA. Nesse tratado vemos a reivindicação por sociedades sustentáveis (como crítica à noção de desenvolvimento sustentável), uma sustentabilidade equitativa, na qual a EA deve estimular a "formação de sociedades socialmente justas e ecologicamente equilibradas, que conservam entre si relação de interdependência e diversidade" (CARVALHO, 2008, p. 56). Em seu princípio número doze o tratado estabelece que a EA "deve ser planejada para capacitar as pessoas a trabalharem conflitos de maneira justa e humana" (CARVALHO, 2008, p. 58).

Ainda nos anos 1990 se fortaleceu a perspectiva da educação no processo de gestão ambiental (promovida pelo IBAMA), período em que começaram a surgir levantamentos sistemáticos e 
análises de conflitos socioambientais. Ampliava-se o debate sobre o caráter público, polêmico e não neutro da gestão ambiental, definida por Quintas (2000) como um processo de mediação de interesses e conflitos entre atores sociais. Segundo esse autor, para um educador que reconhece que a gestão ambiental não pode ser neutra e que sua prática tem caráter intrinsecamente conflituoso, é preciso "comprometer-se com aqueles segmentos da sociedade brasileira que na disputa pelo controle dos bens ambientais do País são sempre excluídos dos processos decisórios e ficam com o maior ônus" (QUINTAS, 2000, p. 19). Vemos aí já uma provocação para o combate das injustiças ambientais, tema intimamente relacionado ao dos conflitos ambientais. Entre os anos 1990 e os anos 2000, cresceu o número de pesquisas, publicações e sítios eletrônicos dedicados a listar, discutir e mapear casos de conflitos socioambientais no Brasil ${ }^{2}$ e no mundo, e entre essas abordagens percebemos algumas críticas dirigidas direta ou indiretamente ao campo da educação ambiental. Cronologicamente: ora se aponta a insuficiência das atividades convencionais de educação ambiental no enfrentamento das implicações ambientalmente indesejáveis dos projetos de desenvolvimento (LEROY; ACSELRAD, 2006); ora se adverte para o perigo da despolitização dos conflitos ambientais a partir das chamadas tecnologias de consenso, situação em que "comunidades de aprendizado" tendem a favorecer a psicologização do dissenso (ACSELRAD, 2004b); outras vezes ainda se denuncia a "pedagogia" de parte do movimento ambientalista voltada para o "esverdeamento do empresariado" (ZHOURI; LASCHEFSKI, 2010). Paralelamente, houve certo fortalecimento de vertentes críticas da EA que nunca perderam de vista suas antigas raízes na ecologia política e, assim, vêm aprofundando seu diálogo com o tema dos conflitos socioambientais (LAYRARGUES, 2000; LOUREIRO, 2009, 2011; CARVALHO, 2008; LIMA, 2011). A forma como definimos "ambiente" torna-se ainda mais relevante para compreendermos e nos posicionarmos perante os debates atuais no campo da EA:

[...] a EA deve auxiliar-nos em uma compreensão do ambiente como um conjunto de práticas sociais permeadas por contradições, problemas e conflitos que tecem a intrincada rede de relações entre os modos de vida humanos e suas formas peculiares de interagir com os elementos físic[o]-naturais de seu entorno, de significá-los e manejá-los. Esses laços de convivência entre os seres humanos e sua base natural de existência estamos chamando de relações sociedade-natureza, e a desarmonia que aí se instaura de conflitos socioambientais. (CARVALHO, 2008, p. 163).

Ao final dos anos 2000 e início dos anos 2010, Zhouri e Laschefski (2010, p. 15-16) veem o "ambientalismo" brasileiro ainda mais dividido que há vinte anos, já que agora são reafirmadas receitas desenvolvimentistas dos anos 1990. Nessa transição, ressurgem polêmicas sobre a gestão ambiental envolvendo os licenciamentos de grandes empreendimentos, e Loureiro (2009) aponta uma especificidade que a educação ambiental estaria conquistando aos poucos: a adoção de uma perspectiva que pretende exercer forte impacto nas políticas públicas e nas relações de poder entre os grupos sociais situados nos territórios que vêm sendo definidos por processos produtivos licenciados". Mas, mesmo com tal inovação, entre as dificuldades e desafios apontados para a educação ambiental brasileira no período atual, Lima (2011) constata a ainda escassa problematização dos conflitos socioambientais.

Vemos, portanto, que algumas vertentes que constroem a própria trajetória de constituição do campo da EA (principalmente as vertentes críticas e populares) acompanham ainda que de modo heterogêneo e não consensual - a trajetória das abordagens sobre os conflitos socioambientais.

\footnotetext{
${ }^{2}$ São exemplos significativos dessa produção: Carvalho e Scotto (1995), Scotto e Limoncic (1997), Acselrad (2004a, 2004b), Acselrad, Herculano e Pádua (2004) e Zhouri, Laschefski e Pereira (2005).
} 


\section{Breves considerações sobre o conceito de conflito social}

Assumindo como sinônimos os termos conflito socioambiental e conflito ambiental e considerando que ambos fazem referência a conflitos sociais, é preciso tentar esclarecer o que é um conflito social e como nossas escolhas teóricas e ideológicas influenciam o resultado de nossas análises nessa temática. Desde suas origens, as Ciências Sociais estudam o fenômeno dos conflitos sociais relacionando-o às pesquisas sobre fatores de mudança ou de conservação de certa ordem social. Tais estudos nos apresentam diferentes concepções sobre as estruturas e dinâmicas das sociedades, influenciados por diferentes visões de mundo, interesses e escolhas metodológicas. Herculano (2006) destaca duas principais abordagens sobre os conflitos sociais nas Ciências Sociais e acrescenta uma terceira perspectiva, na qual os conflitos são irrelevantes como acontecimento social ou devem até ser ocultados.

i) O reconhecimento dos conflitos como uma "doença" social: nessa perspectiva (escola funcionalista), embora não se negue a sua existência, os conflitos são compreendidos como perturbações da ordem social que precisam ser sanadas. O consenso deve ser restabelecido a todo momento e o conflito (dissenso) é uma perturbação temporária e indesejável. Ou, como esclarece Ferreira (2005), nessa abordagem os conflitos são vistos como distúrbios na ordem de sistemas sociais que solicitam esforços para o desenvolvimento de estratégias para neutralizá-los ou mitigálos;

ii) O reconhecimento dos conflitos como constitutivos das sociedades modernas: nessa perspectiva, influenciada tanto pelo pensamento de Max Weber quanto pelo de Karl Marx (embora existam diferenças significativas entre as escolas de pensamento que tais pensadores inauguram), os conflitos são inerentes a qualquer sistema social e atuam como propulsores de mudanças. Ainda que sejam vistos como momentos de ruptura, entende-se que os conflitos são importantes para a dinâmica que historicamente reinventa as sociedades e as identidades dos diferentes atores sociais (HERCULANO, 2006). Inversamente à perspectiva anterior, aqui é o consenso que é visto como uma contingência, não havendo nunca a possibilidade de resolução definitiva dos conflitos sociais (FERREIRA, 2005);

iii) A negação dos conflitos: não explicitamente incluída em uma abordagem científica por Herculano (2006), nessa perspectiva os conflitos são tomados como problemas a serem ocultados, tornados socialmente invisiveis de modo a fortalecer uma visão de sociedade como consenso apenas. É como se um tipo de "paz autoritária" pudesse (e devesse) reger legitimamente a dinâmica social.

Sustentando essas três diferentes visões sobre "o que é" e "o que deve ser" a dinâmica social e seus conflitos, podemos encontrar diferentes conceitos sobre democracia e política, e algumas afinidades parecem emergir entre a primeira e a terceira perspectiva, dominantes em relação à segunda. O filósofo Jacques Rancière critica a ideia dominante de democracia que tem estruturado nossa vida social, regida, segundo ele, por uma ordem policial na qual a prioridade é o controle e vigilância dos comportamentos humanos e sua distribuição nas diferentes porções do território, cumprindo funções consideradas mais ou menos adequadas à ordem vigente (RANCIÈRE, 1996). Para Rancière, a razão de ser da democracia deve ser a própria instituição da Politica, cuja racionalidade é o desentendimento e na qual aqueles que não têm parte reivindicam sua parte por dentro de um dos sistemas de direitos dominantes, criando - por isso mesmo - um campo de contestação. Segundo Marilena Chauí, a democracia é vista pela classe dominante brasileira como o regime da lei e da ordem, mas, para além dessa visão liberal, a democracia deveria ser compreendida como "o único regime político no qual os conflitos são considerados o princípio mesmo de seu funcionamento" (CARIELLO, 2003). Ao impedirmos a expressão dos 
conflitos sociais, segundo a autora, estaríamos destruindo a própria democracia. Entendo que as abordagens desses autores estão mais identificadas com a segunda perspectiva apresentada, segundo a qual os conflitos são inerentes a qualquer sistema social e atuam como propulsores de mudanças, não devendo, portanto, ser sanados, eliminados ou ocultos.

Escolho, desse modo, a segunda abordagem como referência para o desenvolvimento do presente texto, interpretando-a como a mais coerente com os fundamentos políticos, ideológicos, teóricos e metodológicos de uma educação ambiental que se pretende crítica, popular e transformadora, pois apenas nessa abordagem os conflitos são considerados como uma explicitação das contradições sociais (SILVEIRA, 1998) e o princípio do funcionamento da democracia.

Mas, ao elogiarmos um regime político que permite e promove a convivência das diferenças sociais, não estaríamos obrigados a elogiar também as desigualdades sociais e suas causas? Cabe aqui uma diferenciação importante entre pluralidade social e desigualdade social, como sugere Selene Herculano. Podemos considerar correto o reconhecimento do direito à expressão de diferentes visões de mundo, interesses e motivações sociais (diversidade cultural), pois é isso o que caracteriza uma sociedade plural como a nossa (HERCULANO, 2006). Mas podemos considerar pouco razoável a manutenção de desigualdades estruturais - que também caracterizam nossas sociedades -, julgando-as injustas e, portanto, desejando a sua superação. Neste caso, não estamos atribuindo, em nossas escolhas, a mesma legitimidade à pluralidade e à desigualdade. Por esses motivos será importante não nos restringirmos, em nossas análises dos conflitos, à aceitação - a priori - das "regras do jogo" (em grande parte, injustas), mas devemos ficar atentos para a grande contribuição que os conflitos trazem ao questionarem justamente tais "regras", reinventando-as continuamente. Eis o tal "campo de contestação" apontado por Rancière (1996) como racionalidade básica da Política. Daí que muitas das lutas inscritas nos conflitos sociais se deem justamente ao redor da disputa por legitimidade de certos valores e regras sociais contra outros.

\section{Os conflitos ambientais}

São muitos os grupos sociais que lutam pela legitimação de suas formas de uso e acesso aos bens ambientais, assim como pelo reconhecimento de seus saberes e identidades: agricultores familiares, povos indígenas, trabalhadores afetados por condições insalubres de trabalho, quilombolas, pescadores artesanais, seringueiros, moradores das "zonas de sacrifício", ribeirinhos, catadoras de coco-babaçu, associações de moradores em defesa de espaços verdes de lazer e convivência em seus bairros, catadores e recicladores, grupos de mulheres que trabalham com plantas medicinais, entre outros. Entre os agentes agressores que buscam deslegitimar esses grupos é comum encontrarmos o próprio Estado, usinas hidrelétricas, indústrias petroquímicas, agronegócio para exportação, hotéis "ecológicos" de luxo ou aterros sanitários, empresas produtoras de camarão, eucalipto, megaprojetos imobiliários ou turísticos, empresas de agrotóxicos, entre outros. Como se dá esse "encontro", na definição dos conflitos socioambientais? Segundo Acselrad (2004b, p. 26), os conflitos ambientais são

[...] aqueles envolvendo grupos sociais com modos diferenciados de apropriação, uso e significação do território, tendo origem quando pelo menos um dos grupos tem a continuidade das formas sociais de apropriação do meio que desenvolvem ameaçada por impactos indesejáveis - transmitidos pelo solo, água, ar ou sistemas vivos - decorrentes do exercício das práticas de outros grupos. O conflito pode derivar da disputa por apropriação de uma mesma base de recursos, ou de bases distintas mas interconectadas por interações ecossistêmicas mediadas pela atmosfera, pelo solo, pelas águas, etc. 
Uma das dimensões importantes em nossa análise será então a desigualdade de poder de cada ator social em meio ao conflito que vai emergindo, fator que definirá sobre quais grupos sociais recairá prioritariamente a maior carga dos danos ambientais do desenvolvimento: às populações de baixa renda, aos grupos sociais discriminados, aos povos étnicos tradicionais, aos bairros operários, às populações marginalizadas e vulneráveis (ACSELRAD; HERCULANO; PÁDUA, 2001). Enfatizando esse aspecto, Herculano (2006, p. 01) afirma que os conflitos socioambientais são "conflitos entre grupos sociais muito desiguais em termos de poder econômico e político e que se defrontam em disputas que têm no meio ambiente seu epicentro". Segundo a Declaração da Criação da Rede Brasileira de Justiça Ambiental, datada de 2001, a injustiça ambiental é o mecanismo que viabiliza e realiza isso tudo em sociedades como a nossa, desiguais, do ponto de vista econômico e social (ACSELRAD; HERCULANO; PÁDUA, 2001).

Associada a essa dimensão, já podemos entrever outra: o choque entre interesses públicos e privados. Para Carvalho e Scotto (apud HERCULANO, 2006, p. 3), os conflitos socioambientais são conflitos sociais "que têm elementos da natureza como objeto e que expressam as relações de tensão entre interesses coletivos/espaços públicos versus interesses privados/tentativa de apropriação de espaços públicos"3. Lembremos que nossa Constituição Federal de 1988 define em seu artigo número 225 o meio ambiente ecologicamente equilibrado como bem de uso comum do povo e essencial à sadia qualidade de vida, de modo que a desigual apropriação da natureza pelo interesse privado deveria encontrar aí um (potencial) obstáculo para sua legitimação social. Mas, como diz Carvalho (2008, p. 165), vivemos em uma sociedade em que os bens ambientais, assim como outros bens econômicos e sociais, já são - de partida! - objeto de uma distribuição desigual, e "os grupos com maior força econômica e política terminam sobrepondo seus interesses corporativos aos interesses coletivos na distribuição dos bens ambientais". A autora afirma ainda que,

[...] apesar de nossa sociedade ser fundada na ideia de igualdade jurídica dos cidadãos e na universalização dos direitos, na prática das relações sociais, a dinâmica da acumulação privada gera a distribuição desigual de oportunidades e de condições de vida entre os grupos sociais e se nutre dessa desigualdade. Com os bens ambientais não é diferente. Os modos de acesso aos bens ambientais e de seu uso, nos quais prevalecem os interesses privados, além de ocasionarem agressões ambientais, ferem seu caráter coletivo. (CARVALHO, 2008, p. 165-166).

Isso talvez facilite nossa tarefa de interpretação do contexto social e histórico de alguns casos concretos de conflitos ambientais, para além da confusão gerada pela banalização que alguns veículos de comunicação nos oferecem cotidianamente, geralmente criminalizando os movimentos sociais, afinal, tais conflitos:

Dizem respeito a populações deslocadas para a construção de hidrelétricas; a comunidades quilombolas às quais é destinada a instalação de resíduos tóxicos; a aldeias indígenas e grupos quilombolas deslocados por mega-projetos [sic] turísticos e intoxicados pelas monoculturas (do pinus [e do eucalipto] para as fábricas de celulose; da soja); a colônias de pescadores deslocados por megaprojetos imobiliários e turísticos; a mulheres extrativistas - as quebradeiras de babaçu - perseguidas de morte por jagunços de pecuaristas, que cercam e se apropriam dos babaçuais comunais; a aldeias indígenas que vêem seus manguezais secados e cercados, suas águas poluídas pela construção de viveiros de camarões em escala industrial; a pobres suburbanos aos quais é destinada a vizinhança de vazadouro de lixo metropolitano; a crianças pobres, sob tutela do Estado e em cujo educandário o próprio Estado instala fábrica

3 Abordagem desenvolvida também em IBASE (1997). 
de inseticidas; a populações pobres das margens das estradas, que recebem lixo tóxico clandestino proveniente de grandes indústrias; à imposição autoritária de uma usina nuclear sobre uma pequena cidade e seus planos de emergência tratados todavia como secretos. (HERCULANO, 2006, p. 10).

Podemos perceber aí uma grande variedade de situações das quais, diante da necessidade de um aprofundamento analítico, encontraremos sugestões de recortes, entre os pesquisadores do campo dos conflitos ambientais. Zhouri e Laschefski (2010) entendem ser relevante em nossas análises a consideração de três tipos diferentes de conflitos ambientais (ainda que geralmente ocorram sobreposições): i) conflitos ambientais distributivos, ii) conflitos ambientais espaciais e iii) conflitos ambientais territoriais. Em outro enfoque, Acselrad (2004b) considera necessário que as análises desses conflitos levem em conta quatro dimensões que os constituem: a i) apropriação simbólica e a ii) apropriação material da natureza; a iii) durabilidade e a iv) interatividade espacial das práticas sociais.

Gostaria de destacar ainda as dimensões histórica e econômica, integradas às anteriores e sem as quais corremos o risco de descontextualizar nossas análises. Para Herculano (2006, p. 01), os conflitos socioambientais não são fenômenos pontuais e isolados, pois "dizem respeito ao enfrentamento de uma lógica de expansão de fronteiras econômicas por todo o globo e que tem se mostrado deletéria à natureza e aos povos locais". Revendo um pouco da história recente de nosso país, Acselrad (2004b) nos diz que até os anos 1980 grandes projetos de apropriação do espaço foram implementados pelo Estado brasileiro "desenvolvimentista", articulando-se com a implantação de uma complexa estrutura industrial espacialmente concentrada, ocorrendo assim a ampliação dos espaços integrados à dinâmica do desenvolvimento capitalista. Aceleraram-se os ritmos do ciclo industrial de extração de materiais, emissão de efluentes e resíduos, ancorados na concentração da renda e nas exportações. Isso tudo causou grande desestruturação nos ecossistemas, deslocando populações que dependiam dessa base de recursos para áreas menores e menos férteis, levando à intensificação desse uso e comprometendo, com o tempo, sua qualidade. Com a maior abertura democrática nos anos 1980, muitas práticas sociais perseguidas e silenciadas ao longo de duas décadas foram se fortalecendo: novas vozes se expressavam, projetos alternativos conquistavam um espaço público de debate, inovações administrativas eram gestadas na esfera governamental, movimentos sociais começaram a ser reconhecidos em suas lutas por direitos e em suas propostas alternativas de sociedade e os impactos negativos do modelo de desenvolvimento socioeconômico - antes ocultos - puderam vir à tona (ACSELRAD, 2004b).

Ainda segundo Acselrad (2004b), nos anos 1990 acelerou-se a inserção brasileira no mercado capitalista mundializado através da especialização de funções de diferentes porções do território nacional, o que intensificou a corrida pela captação de investimentos internacionais. Nesse modelo, a "natureza" foi concebida ou como estoque de valor para esse mercado (natureza a ser conservada) ou como campo de expansão de empreendimentos incompatíveis com sua conservação (natureza a ser destruída). Para tanto, promoveu-se a flexibilização das normas ambientais e a fragilização das agências públicas responsáveis por sua aplicação. Contra essa intensa "desregulação do ambiente" emergiu um novo momento dos conflitos ambientais no Brasil. Segundo Zhouri, Laschefski e Pereira (2005, p. 13-14), essa foi apenas a consolidação de um processo de despolitização do debate ambiental que já vinha ocorrendo nas décadas passadas, quando o potencial transformador da ecologia política perdeu espaço para um "ambientalismo de resultados", em uma perspectiva economicista hegemônica ${ }^{4}$. Na primeira década do século XXI, Zhouri e Laschefski (2010, p. 15) apontam que, no contexto do Plano de Aceleração do Crescimento (PAC), muitas conquistas no campo socioambiental passaram a ser consideradas como "entraves" ao desenvolvimento:

\footnotetext{
4 A partir de Alier (2007), podemos interpretar essa tendência como integrante da vertente da modernização ecológica, que o autor identifica com a própria ideologia do desenvolvimento sustentável.
} 


\begin{abstract}
Marina Silva perdeu a luta contra os transgênicos e a influência nas políticas para a Amazônia e demais ecossistemas ameaçados. No âmbito do Plano de Aceleração do Crescimento (PAC), foram retomados grandes projetos de infra-estrutura, como hidrelétricas, hidrovias, rodovias, portos, entre outros, ao longo dos antigos eixos de desenvolvimento, dessa vez com a perspectiva da "inclusão internacional" da nação ao mercado global. Observa-se que os ganhos ambientais, como o código florestal, o licenciamento ambiental, os planos de mitigação e de compensação ambiental, as propostas para [a] realização dos Zoneamentos Ecológicos Econômicos (ZEEs) e os direitos dos grupos indígenas, quilombolas e povos tradicionais ancorados na Constituição de 1988, têm sido considerados como "entraves" ao desenvolvimento.
\end{abstract}

\title{
4. Algumas implicações metodológicas para a abordagem dos conflitos
}

Diferentemente de outros conceitos que mais diretamente nos convidam a reinvenções metodológicas em nossa práxis no campo da educação ambiental, o conceito de conflitos socioambientais refere-se a um acontecimento social e histórico. Nesse sentido, trago aqui algumas reflexões (e escolhas teóricas, políticas, ideológicas) a partir da interpretação do que considero coerente e urgente para o fortalecimento da abordagem dos conflitos socioambientais na EA, suas peculiaridades e desafios metodológicos.

\section{a) As características de nosso coletivo de educandos-educadores}

São muitas as possibilidades de abordagem do tema dos conflitos socioambientais considerando-se os diferentes contextos de nossa práxis educativa, de modo que é necessário investigar a adequação na estratégia e grau de mobilização de saberes. Qualquer que seja essa condição, sempre haverá uma possibilidade de se conhecer um pouco mais criticamente algo sobre a sociedade e o mundo em que vivemos a partir das muitas provocações que um caso concreto de conflito ambiental pode nos trazer, se assumirmos uma atitude de investigação e de debate, em processos coletivos. No entanto, concordando com Loureiro (2009), entendo que projetos de EA que pretendam abordar a conflituosidade socioambiental que aqui destaco como nos processos de licenciamento ambiental - precisam delimitar os sujeitos do processo educativo em consonância com as citadas escolhas teóricas e políticas.

Quando nos encontramos frente a um tratamento deshistoricizado [sic] [...] que preconcebe o ambiente como categoria do consenso e da cooperação, ignorando sua dimensão de contestação e de conflito, as atividades educativas tendem a voltar-se para a sensibilização e para a transmissão de conceitos abstratamente. Não há, neste escopo de ações, preocupação em se organizar as atividades a partir de e com foco nos grupos prioritários do processo educativo (os que se encontram em situação de maior vulnerabilidade socioambiental). (LOUREIRO, 2009).

Processos e projetos de educação ambiental com o propósito de atuar nessa temática e que se voltam a um público genérico ("população em geral", "representantes da sociedade civil") tendem a se emaranhar em uma atmosfera consensual e avessa a polêmicas que dificulta a tematização das desigualdades socioambientais e das práticas de diferentes atores sociais nos conflitos estudados. O teor crítico que desejamos na abordagem dos conflitos exige fôlego e disposição para se cavoucar coletivamente o que foi historicamente soterrado, implica escolhas e antagoniza-se com discursos hegemônicos e abstrações. É nesse sentido também que Loureiro (2009) critica a exagerada ênfase, no contexto dos licenciamentos, na educação formal e no 
público infantojuvenil, desviando-se dos grupos prioritários, de maior vulnerabilidade socioambiental. Ou seja, a própria delimitação dos sujeitos da ação educativa já inaugura uma manifestação de conflituosidade social, uma vez aceita a não neutralidade da educação.

\section{b) É fundamental, em nossa práxis, o estímulo à atitude de pesquisa no âmbito dos conflitos}

Se pudermos desenvolver nossas investigações estando próximos do contexto do conflito que está ocorrendo, na duração de seu acontecimento, tanto melhor; colecionando reportagens, desenvolvendo entrevistas, produzindo audiovisuais e colaborando com os movimentos sociais para a disponibilização e geração de informações e análises específicas de certos fenômenos (biológicos, físico-químicos, fisiológicos etc.), geralmente relevantes no enfrentamento da dinâmica dos conflitos ambientais. Nessas situações de pesquisa de campo, é preciso também tomarmos as devidas precauções e estarmos atentos a certos limites, quando o contexto do conflito pode incluir situações explícitas de violência, risco de contaminações, de perseguições políticas etc. $O$ próprio processo coletivo de pesquisa-intervenção, assumido publicamente, acionador de muitas redes e mídias, já pode ser, em si, uma forma de precaução. Dado o caráter polêmico dos conflitos, assim como fazemos em muitas pesquisas em ciências sociais, é preciso zelar também pela segurança dos depoentes.

\section{c) $O$ aprofundamento na pesquisa sobre um caso de conflito socioambiental}

A escolha dos casos que se quer abordar no coletivo já pode ser a primeira tarefa de nossa pesquisa coletiva. Recorrendo a jornais, livros, internet, ou entrevistas, podemos colecionar algumas das situações de conflitos que nos são próximas e isso pode fortalecer, com o apoio de outras áreas de conhecimento, a construção de uma visão mais interdisciplinar e contextualizada do socioambiente em que vivemos, o que gerando muitas oportunidades para várias outras abordagens de ensino e aprendizagem. O nível de polêmica que essa escolha venha a trazer em nossos círculos de convivência já é em si mesmo um indicativo da relevância do tema e do desafio de se desvelar o jogo de poderes sociais em ação no cotidiano. Mesmo escolhendo um caso de conflito mais distante de nossa realidade, poderemos, com grande proveito, aprender muito sobre a dinâmica histórica de nossas sociedades e os confrontos entre diferentes formas de apropriação e uso da natureza.

Algumas perguntas - inspiradas em pesquisas das ciências sociais - podem nos ajudar na reflexão e debate coletivos sobre os conflitos ambientais: qual é a situação específica de conflito? Como são descritas as dimensões histórica, geográfica, ecológica, política, econômica, cultural etc. dessa situação? Tente conseguir informações sobre como essa situação foi alcançando a opinião pública. Qual a fonte das informações que o coletivo está trabalhando? Tente colecionar diferentes fontes (pesquise os discursos que circulam na mídia) e perceber os diferentes interesses e posições ideológicas que guiam as diferentes narrativas sobre o caso em questão. Quais os atores sociais envolvidos e como eles agem? Quais visões de mundo, interesses e valores guiam seus modos de ser e agir? O que é reivindicado a cada parte? Que argumentos e justificativas são utilizados? Como é a distribuição da carga de impactos ambientais negativos entre os diferentes atores sociais envolvidos? Que recursos de poder são acionados ou gerados em meio ao conflito? Qual tem sido o desempenho dos órgãos públicos no acionamento dos dispositivos legais para a proteção e gestão ambiental?

\section{d) Entre a pesquisa, o debate, o processo formativo e a ação}

Em função das escolhas pedagógicas possíveis e adequadas a cada círculo formativo, estaremos mais próximos ou não dos grupos prioritários do processo educativo (vulneráveis e 
vulnerabilizados pelo conflito). Se desejamos um material didático já estruturado, de fácil acesso e traduzível a variados espaços educativos (com destaque para a educação formal), o "Projeto PROBIO Educação Ambiental" 5 criou uma proposta pedagógica voltada à problematização das ameaças aos biomas brasileiros identificadas como casos de conflitos socioambientais (ou situaçôes-problema). Se estivermos um pouco mais próximos do acontecimento do conflito, em potencial colaboração com os grupos vulnerabilizados, o aprendizado e a vivência da metodologia da pesquisa-ação podem ser mais relevantes e coerentes, envolvendo, porém, maior complexidade em nossa práxis educativa. E, se estivermos diretamente envolvidos com atores sociais que iniciam sua luta contra alguma injustiça ambiental em meio ao conflito já instalado, perceberemos a urgência do processo de manejo de saberes e da realização de ações organizadas e efetivas. No polêmico contexto dos processos de licenciamentos ambientais de empreendimentos, nossa práxis educativa pode colaborar para que i) informações pertinentes sejam publicamente apropriadas, ii) conhecimentos sejam produzidos de modo a permitir o posicionamento responsável e qualificado dos agentes sociais envolvidos e também para garantir que iii) exista a ampla participação e mobilização dos grupos afetados em todas as etapas do licenciamento e nas instâncias públicas decisórias (LOUREIRO, 2009). De modo geral, podemos colaborar para uma rápida conexão com a experiência de outros movimentos sociais e, nesse sentido, a divulgação e a vivência de propostas como o "Projeto Avaliação de Equidade Ambiental", o "Projeto Nova Cartografia Social da Amazônia" e o "I Seminário Brasileiro contra o Racismo Ambiental" (HERCULANO; PACHECO, 2006) podem ser de grande valia.

\section{Indicadores para avaliação de nossas abordagens e questões para o debate}

Sugiro aqui, inspirado no roteiro citado, alguns indicadores para avaliarmos o alcance de nossas abordagens no tema dos conflitos socioambientais, além de algumas outras questões para o debate:

- Contextualização: pesquisa histórica sobre o contexto geral de onde emerge o conflito. É importante tentarmos colecionar e debater informações sobre como foi se construindo tal "acontecimento". É importante que se conheça a lógica econômica que predominou no contexto: que políticas apoiaram os empreendimentos que levaram à emergência do conflito? Qual a condição socioeconômica das populações afetadas? Quais segmentos sociais mais se favoreceram com essa situação? Como as informações sobre os riscos e danos fluem (ou não) entre os diferentes círculos de envolvidos, nas mídias e para o público em geral?

- Anunciar a pluralidade e denunciar a desigualdade: consideração da diversidade social territorializada no contexto do conflito. Para além do que apontam os relatórios oficiais sustentados pelo governo, técnicos, cientistas e empresas, seria importante nos perguntarmos: que outras formas de apropriação social do território estão (ou estavam) existindo ali, tanto na

\footnotetext{
${ }^{5}$ Disponível em: http://www.ecoa.unb.br/probioea/. Na estruturação desta metodologia encontramos referências ao método Paulo Freire, envolvendo pesquisas que levaram à codificação de situações socioambientais consideradas problemáticas em cada bioma, e que acionadas como temas geradores, oferecem aos educadores caminhos alternativos para a decodificação nos processos formativos, além de incluir um jogo e um livro de apoio ao professor. Agradeço à Jacy Bandeira Almeida Nunes e Marcone Denys dos Reis Nunes (Universidade do Estado da Bahia - Campus de Jacobina) pelos esclarecimentos sobre a construção metodológica do projeto e pela doação de materiais.

${ }^{6}$ Disponível em: http://www.fase.org.br/v2/pagina.php?id=3719 . Agradeço a Gabriela Scotto (UFF) e Julianna Malerba (FASE) pelo convite a uma oficina do projeto e doação de materiais.

7 Disponível em: http://www.novacartografiasocial.com/. Agradeço a Franklin P. Carvalho (pesquisador do projeto) pela apresentação da proposta e compartilhamento de materiais referentes ao projeto.
} 
sua dimensão material (sobrevivência, bens, produção e consumo, comércio, circulação, saúde, lazer) quanto simbólica (visões de mundo, significados, crenças, memórias, saberes e representações)?

- Explicitar o que vem sendo oculto: debater aspectos "desconsiderados" no conflito. Nos discursos e pesquisas oficiais geralmente estão mais bem representados aspectos que mais interessam aos donos e sócios dos próprios empreendimentos, e muitas das dimensões para as quais historicamente reivindicamos a atenção e proteção pública - "outras" relações entre cultura e natureza - ficam invisíveis, geralmente porque estão sendo ativamente invisibilizadas. Pode estar sendo desconsiderada uma área ou um impacto específico, uma prática social, outra visão de economia etc. Nossas pesquisas e debates estão conseguindo trazer à tona aspectos geralmente "desconsiderados" em estudos oficiais (tais como os EIA/RIMA) ${ }^{8}$ ?

- Estranhar a via única do "natural" e se familiarizar com as muitas alternativas estranhas: vivemos mergulhados em uma cultura dominante que promove a homogeneização de hábitos, costumes, saberes, sonhos, significados, certezas, padrões estéticos e linguísticos etc. Essa pressão pela "igualdade" cultural é um dispositivo de manutenção da desigualdade social promovido pela aliança de economia e política dominantes, fornecendo-lhes um arsenal de recursos para a legitimação de todo um modelo de desenvolvimento econômico (capitalista), ao mesmo tempo que busca deslegitimar resistências e lutas contra as injustiças sociais e ambientais daí decorrentes. Quais os diferentes significados e valores dos diferentes grupos sociais envolvidos nos conflitos? Como esses grupos compreendem o próprio conflito? Quais suas propostas de alternativas de "felicidade" (diferentes das oficiais), pelas quais lutam? Estamos conseguindo colaborar para que suas vozes alcancem o espaço público? Por que algumas situações de degradação ambiental e de injustiça social emergem como conflitos socioambientais e outras não?

- O caráter público do ambiente equilibrado versus a privatização do ambientemercadoria. Aqui poderíamos avaliar nossas conquistas nas pesquisas, debates e ações em termos de um duplo critério, de fato, "socioambiental". Discordando de uma visão que diz que o ambiente só é bem protegido se for privatizado e se tiver valor no mercado e discordando também de outra visão que diz que a conservação da natureza só interessa às classes médias urbanas (como um interesse estético e romântico), é importante verificarmos como se dá a coincidência entre desigualdade/injustiça social e degradação ambiental, no contexto do conflito considerado. Há concentração dos riscos ambientais sobre as populações mais vulneráveis e mais vulnerabilizadas? Se há, como se explica isso diante dos nossos ordenamentos jurídicos e da competência de órgãos de proteção ambiental? Estamos conseguindo problematizar em nossas pesquisas a associação entre privatização da natureza, desigualdade social e desequilíbrio ecológico? Ou continuamos a separar "sociedade" e "natureza" no estudo dos conflitos ambientais (conservação ambiental "objetiva" de um lado e justiça social "fora do ambiente" de outro)? Será proveitoso conhecermos, a fundo, o conceito de justiça ambiental, que nos ajudará a romper tal dicotomia.

\section{Para continuidade e aprofundamento}

Faço a seguir algumas sugestões de documentários, sítios eletrônicos e organizações nos quais se pode conhecer muitas pesquisas e experiências concretas de enfrentamento de injustiças nas situações de conflitos socioambientais:

${ }^{8}$ Estudo de Impacto Ambiental / Relatório de Impacto Ambiental. 
Documentários (alguns deles estão disponíveis na internet)

DA MARGEM AO CENTRO: o outro lado do desenvolvimento. Produção: PACS. Rio de Janeiro, 2009. Duração: 34 min.

O CHAMADO DO MADEIRA: a luta dos povos da Amazônia contra os megaprojetos. Produção: Rede Brasil/ActionAid. Direção: Andréa Rossi. Duração: 45 min.

BELO MONTE: anúncio de uma guerra. Produção: Cinedelia.

O VENENO ESTÁ NA MESA. De Silvio Tendler. Produção: Caliban. Apoio: EPSJV-Fiocruz. Ano: 2011. Duração: 50 min./cor.

\section{Sítios eletrônicos sobre mapeamentos de conflitos socioambientais}

http://www.conflitoambiental.icict.fiocruz.br/

http://conflitosambientaismg.lcc.ufmg.br/

http://www.observaconflitos.ippur.ufrj.br/novo/ajax/indexajax2.asp

Algumas das organizações que realizam pesquisas sobre conflitos socioambientais

FASE (Projeto Brasil Democrático e Sustentável)

PROJETO NOVA CARTOGRAFIA SOCIAL DA AMAZÔNIA

JUSTIÇA NOS TRILHOS

MOVIMENTO DOS ATINGIDOS POR BARRAGENS

COMISSÃO PASTORAL DA TERRA

OBSERVATÓRIOS DE CONFLITOS URBANOS (IPPUR/UFRJ)

\section{Referências}

ACSELRAD, Henri (Org.). Conflito social e meio ambiente no Estado do Rio de Janeiro. Rio de Janeiro: Relume Dumará/FASE, 2004a.

ACSELRAD, Henri. Apresentação. As práticas espaciais e o campo dos conflitos ambientais. In: (Org.). Conflitos Ambientais no Brasil. Rio de Janeiro: Relume Dumará/FASE, 2004b.

ACSELRAD, Henri; HERCULANO, Selene; PÁDUA, José Augusto (Org.). Justiça Ambiental e Cidadania. Rio de Janeiro: Relume Dumará/Fundação Ford, 2004.

ALIER, Joan Martínez. O ecologismo dos pobres. São Paulo: Contexto, 2007.

CARIELLO, Rafael. Democracia é conflito, não ordem, diz filósofa (entrevista com Marilena Chauî). Folba de São Paulo, São Paulo, 03 ago. 2003. Disponível em: < http://www1.folha.uol.com.br/folha/brasil/ult96u51892.shtml > . Acesso em: 07 jul. 2013.

CARVALHO, Isabel Cristina de Moura. Educação Ambiental: a formação do sujeito ecológico. 3. ed. São Paulo: Cortez, 2008.

CARVALHO, Isabel Cristina de Moura; SCOTTO, María Gabriela. Conflitos sócio-ambientais no Brasil. Rio de Janeiro: IBASE, 1995. (v. 1). 
FERREIRA, Lúcia da Costa. Conflitos sociais e uso de recursos naturais: breves comentários sobre modelos teóricos e linhas de pesquisa. Política \& Sociedade, n. 7, p. 105-118, out. 2005.

HERCULANO, Selene. Lá como cá: conflito, injustiça e racismo ambiental. In: SEMINÁRIO CEARENSE CONTRA O RACISMO AMBIENTAL, 2006, Fortaleza. Disponível em: $<$ http://www.professores.uff.br/seleneherculano/images/stories/L como c3.pdf $>$. Acesso em: 25 fev. 2013.

HERCULANO, Selene; PACHECO, Tania. (Org.). Racismo Ambiental: I Seminário Brasileiro sobre Racismo Ambiental. Rio de Janeiro: Projeto Brasil Sustentável e Democrático/FASE, 2006.

IBASE - INSTITUTO BRASILEIRO DE ANÁLISES SOCIAIS E ECONÔMICAS. Conflitos ambientais no Brasil: natureza para todos ou somente para alguns? Supervisão geral de María Gabriela Scotto e redação de Angela Ramalho Vianna. Rio de Janeiro: IBASE, 1997.

LAYRARGUES, Philippe Pomier. Educação para a gestão ambiental: a cidadania no enfrentamento político dos conflitos socioambientais. In: LOUREIRO, Carlos Frederico Bernardo; LAYRARGUES, Philippe Pomier; CASTRO, Ronaldo Souza de (Org.). Sociedade e Meio Ambiente: A educação ambiental em debate. São Paulo: Cortez, 2000. p. 87-155.

LEROY, Jean Pierre; ACSELRAD, Henri (Coord.). Mapa dos conflitos ambientais no Estado do Rio de Janeiro. Rio de Janeiro: FASE/BSD, ETTERN/IPPUR/UFRJ, 2006. (CD-ROM)

LIMA, Gustavo Ferreira da Costa. Educação Ambiental no Brasil - formação, identidades e desafios. Campinas, SP: Papirus, 2011.

LOUREIRO, Carlos Frederico Bernardo. Educação ambiental no licenciamento: aspectos legais e teórico-metodológicos. In: (Org.). Educação ambiental no contexto de medidas mitigadoras e compensatórias: o caso do licenciamento. Salvador: IMA, 2009.

LOUREIRO, Carlos Frederico Bernardo. Educação ambiental e movimentos sociais na construção da cidadania ecológica e planetária. In: LOUREIRO, Carlos Frederico Bernardo; LAYRARGUES, Philippe Pomier; CASTRO, Ronaldo Souza de (Org.). Educação ambiental: repensando o espaço da cidadania. 5. ed. São Paulo: Cortez, 2011. p. 73-103.

QUINTAS, José Silva. Por uma educação ambiental emancipatória: considerações sobre a formação do educador para atuar no processo de gestão ambiental. In: (Org.). Pensando e praticando a educação ambiental na gestão do meio ambiente. Brasília: IBAMA, 2000. p. 11-19.

RANCIÈRE, Jacques. O desentendimento: política e filosofia. Tradução de Ângela Leite Lopes. São Paulo: 34, 1996.

SCOTTO, María Gabriela; LIMONCIC, Flávio (Org.). Conflitos sócio-ambientais no Brasil. Rio de Janeiro: IBASE, 1997. (v. 2).

SCOTTO, María Gabriela; CARVALHO, Isabel Cristina de Moura; GUIMARÃES, Leandro Belinaso. Desenvolvimento Sustentável. Petrópolis, RJ: Vozes, 2007.

SILVEIRA, Ricardo de Jesus. Unidade VI - Os movimentos sociais. In: TOMAZI, Nelson Dacio (Coord.). Iniciação à sociologia. São Paulo: Atual, 1998. p. 207-221. 
Pesquisa em Educação Ambiental, vol. 8, n. 2 - pp 31-44 , 2013

ZHOURI, Andréa; LASCHEFSKI, Klemens (Org.). Desenvolvimento e conflitos ambientais. Belo Horizonte: Ed. UFMG, 2010.

ZHOURI, Andréa; LASCHEFSKI, Klemens; PEREIRA, Doralice Barros (Org.). A insustentável leveza da política ambiental: desenvolvimento e conflitos socioambientais. Belo Horizonte: Autêntica, 2005.

Artigo submetido em 08/07/2013

Artigo aprovado em 18/09/2013 